\title{
A six-lead heart monitor on your smartphone: an interview with David Albert
}

\author{
David Albert*,1 \\ ${ }^{1}$ AliveCor, Inc. 444 Castro St \#600, Mountain View, CA 94041, USA \\ *Author for correspondence: drdave@alivecor.com
}

First draft submitted: 10 October 2019; Published online: 5 December 2019

Keywords: AliveCor • arrhythmia • ECG • heart monitoring • smartphone

David E Albert, MD, has graduated with Honors from Harvard College (MA, USA) and from Duke University School of Medicine (NC, USA). An Oklahoma (USA) native, Albert is a physician, inventor and serial entrepreneur who has developed medical and other life-saving technologies and products over the last 35 years, turning a number of those innovations into tech startups. He is a founder and Chief Medical Officer of AliveCor (CA, USA) and is the inventor of the AliveCor ${ }^{\circledR}$ Kardia $^{T M}$ technology. His previous startups include Corazonix Corp (sold to Arrhythmia Research Technology) and Data Critical (sold to GE Medical Systems Information Technologies). Albert has 65 issued US patents, and a large number of international and pending patents. He has authored or co-authored over 100 scientific abstracts and publications, principally in the cardiology field. Albert has also lectured at universities and leading medical centers all over the world and is a regular faculty member at major cardiology scientific meetings.

In this exclusive interview, David Albert discusses KardiaMobile 6L, the first personal six-lead electrocardiogram (ECG) device. This interview was conducted by Julia Titova, Commissioning Editor of Future Cardiology.

Please tell me about yourself \& your career to date. What first drew you to this area of work? I characterize myself as an inventor, who just happened to be trained as a doctor. While studying at the Duke University School of Medicine, I became interested in understanding how the equipment I used every day to conduct basic science research worked. Shortly before completing my medical degree, I left to study engineering at the Duke University. This education in engineering was critical in my journey in becoming an inventor. After this, I returned to finish medical school and during this time, and while in my postgraduate training at the University of Oklahoma (OK, USA), I invented and patented a number of devices. In the late 1980s, I decided to get out of the academic medicine and become an entrepreneur. At that time, my wife certainly did not approve but thankfully, it worked out for me. Now, 30 years on, I have 65 patents and have started four companies. AliveCor began in 2011 and we have continued to grow since.

\section{AliveCor recently announced the UK launch of KardiaMobile 6L, the first US FDA-approved six-lead personal ECG. Could you tell me about this technology \& how it works?}

Around 1995, it was the beginning of handheld computing technology and wireless data. I realized that it would be amazing for a patient to be able to send data directly to a doctor, which led to the development of the idea and the first prototype for KardiaMobile. Our most recent device, KardiaMobile 6L, provides the first personal solution for capturing Einthoven's Triangle, which enables the recording of all six limb leads, or half of the standard 12-lead ECG.

The majority of KardiaMobile users suffer from the most common arrhythmia, atrial fibrillation (AF). With millions of people around the world suffering from AF, it is a major cause of significant strokes. Since the launch, we have recorded over 50 million ECGs and are now used by major medical centers around the world. The cloud enables us to connect individual patient ECGs to their doctors and hospitals seamlessly.

Of course, there is the danger of what some call an 'e-hypochondriac'. For example, several years ago, a colleague called me into his office and, with a scowl on his face, said: "I gave one of your devices to one of my patients and he sent me 25 ECGs in the first day!" Since then we have improved this technology and over 50\% of our devices are

Future $\because$ Medicine 
bought by patients on the recommendation of their doctor. 'E-hypochondriacs' are much less of a concern today, as patients are becoming more engaged in their own care, enabling them to take more responsibility for their own health and have a better understanding of their conditions.

\section{How does this advance current technology? How does the accuracy compare to a single lead device?}

Our original device was a very simple device: a case with two electrodes that used a smartphone to record a single-lead ECG. We recently introduced the new KardiaMobile 6L, which, by providing all six limb leads, enables a myriad of additional diagnoses over the single lead, including measurement of the QRS (main component of the electrocardiogram and represents the electrical signal which controls the pumping of the heart) and T-wave axis. Additionally, it also measures the QT interval (most often done with Lead II), which is the time duration from the beginning of the heart's pumping to the end of its relaxation before another beat. A prolongation of the QT internal creates significant risk for a serious and potentially fatal cardiac arrhythmia. It also improves visualization of P-waves, which will enable improved identification of AF, as well as the diagnosis of atrial flutter. We are conducting studies to prove these advanced features and to gain FDA clearance in order to make claims regarding these advantages. This advance should provide a quantum leap in terms of information for your cardiologist. There are now many other conditions that can be diagnosed and a lot more information that can be very useful for the management of patients. We will be conducting clinical studies to prove this.

KardiaMobile $6 \mathrm{~L}$ is not only convenient, but it is with you all the time and is inexpensive. Unlike many medical technologies, KardiaMobile is one that people can afford themselves, yet it is a CE marked, FDA cleared medical product, which gives you clinical quality data. We have over 80 peer-reviewed publications based on various studies that have been conducted. For example, FDA requested that we compare the six leads from the KardiaMobile 6L to the same leads from a standard 12-lead ECG, which demonstrated clinical equivalence.

\section{What were some of the biggest challenges in the product's development \& in getting its approval from FDA?}

We have developed personal ECG devices before and we followed the same clinical validation formula that worked previously to facilitate FDA and CE clearances. The challenge was that there were only a few examples of consumer devices also gaining approval from the FDA as a medical device, so the navigation of the whole process and the advertising techniques to be used for this new device were largely unknown. When we started in 2011, there were no models for true medical devices that are both medical and consumer devices. The only thing that is analogous is a blood pressure cuff. How do you sell directly to consumers yet have doctors still consider it as a real medical device?

We also spent a lot of time on ensuring that the device was completely validated by solid research, so we published a study around it ahead of our submission for FDA approval. As a result, the approval for the device took only 70 days. Since then, numerous more studies have taken place and we have received a number of FDA and CE clearances. We are now used as an example of how digital health should lead with validation and evidence-based research.

\section{What are the next steps in the development of this technology? Where do you think heart-monitoring technology will be in the next 10 years \& what challenges will the field need to overcome?}

I am not going to give away any secrets but we consider the KardiaMobile 6L to be a platform that will support a number of new clinical applications. Going from one lead to six leads, it still gives personal ECG data that anyone can use to record their own clinical quality data. I would also see AliveCor participating in other areas, like the detection and diagnosis of heart attacks, heart failure, hypertension and high blood pressure. We are going to make sure that we continue to empower patients, as well as deliver accurate data to physicians that improves the management, diagnosis and outcomes for the patients.

I think in the next decade, you will see the medical capabilities of wearables, such as those produced by Google, Amazon and Apple, becoming more and more proficient in their medical capabilities. They will blur the line between a consumer device and a medical device, which I think will ultimately benefit the patient. 


\section{What would you say has been the most memorable \& exciting moment of your career?}

We have had many people contact us and thank us for saving their life or the life of a loved one with AliveCor technology. Every time that happens, it makes me smile because my 'crazy idea' is bringing real value to the world. I feel like I have made a difference and accomplished something significant, which I am very proud of.

\section{Disclaimer}

The opinions expressed in this interview are those of D Albert and do not necessarily reflect the views of Future Medicine Ltd/Future Science Ltd/Newlands Press Ltd.

Financial \& competing interests disclosure

D Albert is the founder and Chief Medical Officer of AliveCor and a member of the Board of Directors. He owns a significant equity in and receive significant salary income from AliveCor. The author has no other relevant affiliations or financial involvement with any organization or entity with a financial interest in or financial conflict with the subject matter or materials discussed in the manuscript apart from those disclosed.

No writing assistance was utilized in the production of this manuscript. 
